\title{
Development of smartphone application for personalized physical fitness education for university students in COVID-19 pandemic era
}

DOI:10.36909/jer.ASSEEE.16057

\author{
Adang Suherman, Kuston Sultoni*, Jajat
}

Faculty of Sport and Health Education, Universitas Pendidikan Indonesia, Jl. Dr. Setiabudi no 229, Bandung 40154, Indonesia.

*Email: kuston.sultoni@upi.edu; Corresponding Author.

\begin{abstract}
Online distance learning during the COVID-19 pandemic can impact decreasing physical activity and increasing sedentary behaviour, leading to the reduced physical fitness of students. The research aims to develop an android application (app) to assist students in developing physical fitness independently. Four stages of development have been carried out to create the Mahasiswa Bugar application. The advantages of the Mahasiswa Bugar app are as a guide to measuring physical fitness that can be done by students themselves and based on existing literature. Physical fitness test items guided through this application are health-related fitness, body composition, cardiorespiratory fitness, muscle strength and endurance, and flexibility, including features for feedback, history or recording of test results and training program. The results of the quasi-experiment show that the percentage of student involvement in vigorous physical activity has increased. Although the fit student android application's socialization did not significantly impact increasing the intensity of physical activity and motivation to train, this application could be a solution for students in fostering physical fitness independently during the COVID-19 pandemic.
\end{abstract}

Key words: COVID-19, smartphone application, physical fitness. 


\section{INTRODUCTION}

Large-Scale Social Restriction (usually called PSBB) is one way that the government has implemented in preventing the spread of COVID-19 in Indonesia. The purpose of implementing the PSBB is to minimize interactions so that it is hoped that it can break the cycle of the spread of COVID-19. In other words, PSBB limits social space or quarantines the community. The strict quarantine has been proven to reduce the spread of the Covid-19 outbreak more widely (Piguillem \& Shi, 2020; Sjödin et al., 2020). The PSBB policy requires that all activities be carried out at home, both work and learning activities.

This policy certainly creates new problems in terms of economic activity (Moser \& Yared, 2020) and other activities, such as decreased physical activity behaviour (Hammami et al., 2020). Meanwhile, the long-term negative impact that can occur is an increase in the risk burden of NCD (Mattioli \& Ballerini Puviani, 2020). In addition to being the leading cause of death globally (World Health Organization, 2018), NCD is also a comorbidity or comorbid disease that can worsen patients exposed to Covid-19 with advanced mortality (Pal \& Bhadada, 2020).

One of the community groups affected by the PSBB policy is students who have to carry out learning activities at home. As an age group with a transition period, students tend to decrease in physical activity (Cocca et al., 2014). This condition is coupled with learning activities carried out online and requiring students to sit in front of a screen a lot, which increases student sedentary behaviour. Therefore, the world is currently faced with two pandemics simultaneously, namely Covid-19 and sedentary behaviour (Nyenhuis et al., 2020). To overcome the physical inactivity problems, recommendations and practical instructions are needed to stay active in physical activity at home (Hammami et al., 2020) during the Covid-19 pandemic. 
Many platforms and technologies are offered as training guides in videos and other smartphone applications (Arigo et al., 2020). However, most platforms only focus on training guides, while those that include fitness test instructions are relatively limited. These test instructions are essential to understand how the initial condition of health and fitness they have to determine the right dose of physical activity or exercise program. The correct quantity of physical activity is necessary to impact health (Ekelund et al., 2020) positively. The dosage referred to in the physical activity program is related to the frequency, intensity, time and type of activity carried out (FITT principle). The correct application of FITT principles in physical activity can benefit health and fitness and prevent medical disability (Kassa \& Grace, 2020). Based on these problems, the purpose of this study is to develop an android application (mobile apps) that can be used as a guide in measuring fitness conditions and an independent physical fitness program guide for students during the COVID-19 pandemic. The advantage of this android application called Mahasiswa Bugar is that students can measure their physical fitness individually and get physical activity program instructions according to the test results obtained according to literature recommendations from experts. Physical fitness test items guided through this application are health-related fitness component. The component is consisting of body composition (BMI and fat percentage), cardiorespiratory fitness (PACER test), muscle strength and endurance (push-ups and curl-ups) and flexibility (v-sit and reach).

\section{METHODS}

\section{Procedure}

This research procedure uses a research development method (Gall et al., 2003) which consists of ten stages of research. However, in this study, the procedure is simplified into four stages which summarize the ten stages. The four stages are (1) Requirements analysis and application design; (2) Application development; (3) Trial and Modification; and (4) Quasi experiment. 
Figure 1 below is a flowchart of this research framework.

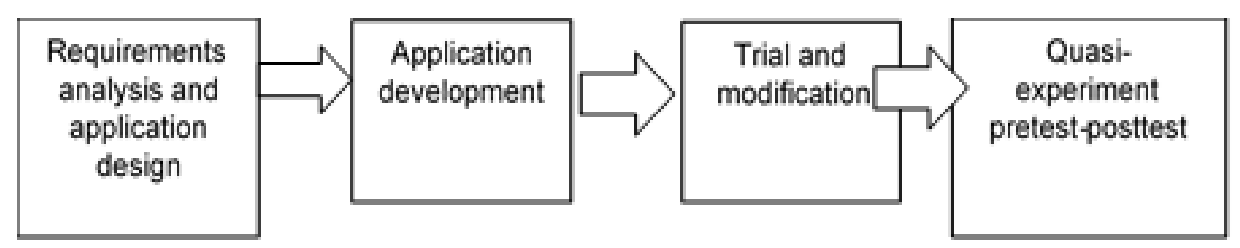

Figure 1: Research and Development Framework

Requirements analysis and application design. In the early stages of this research, identification and needs analysis were carried out about what applications are needed and what features are needed in designing applications for independent physical fitness coaching for students. Data in the form of physical activity questionnaires, knowledge of fitness, and student demographic data were collected and analyzed to produce design principles which were then developed into a prototype which would be developed at the next stage.

Application development. At this stage, the student fitness application prototype is made based on the initial design principles developed in the first stage-application design in user experience (UX) and user interface (UI). UX is in the form of a framework chart of how the application will run, and the UI is the design of the application display design. UX was developed by the research team, while the UI was developed together with visual design experts to make the application look more attractive. After the UX and UI are developed, then at this stage an application development is carried out using the Android Studio in collaboration with application developers.

Trial and modification. The prototype in the form of a student fitness application created in the second stage was then tested and modified together with the application developer and then published to the Google Play store. 
Quasi-experiment pre-test post-test. At this stage, a quasi-experiment pre-test post-test was carried out to answer two research questions. First, is there an increase in the level of physical activity before and after getting the socialization of the Mahasiswa Bugar application? The second question is whether there is an increase in the motivation to do students' physical activity before and after getting the socialization of the Mahasiswa Bugar application? The research method to answer these research questions is designed as follows:

\section{Participants}

Participants are recruited through posters/flyers distributed to students of Universitas Pendidikan Indonesia who have contracted physical education courses. There were 71 volunteer students to be the research sample and took part in the pre-test, but only 48 students took the post-test, and there were eight invalid data, so the total data analyzed at this stage was 40 samples.

\section{Instruments}

The instruments used in the pre-test and post-test were the International Physical Activity Questionnaire short form (IPAQ-SF) (Capdevila Ortís et al., 2007) and the Behavioral Regulation in Exercise Questionnaire-2 (BREQ-2) (Markland \& Tobin, 2004). IPAQ is a valid and reliable instrument for measuring the level of physical activity by asking about the duration and frequency of vigorous, moderate physical activity, walking time, and sitting time for the last seven days.

\section{Intervention}

The intervention was carried out by initializing the application by holding an online workshop on using the Mahasiswa Bugar application for 2 hours for students at the Universitas Pendidikan Indonesia. The workshop was conducted through a Zoom webinar and was open to students of the Universitas Pendidikan Indonesian. 
After the workshop was complete, students were allowed to ask questions related to the application and students were allowed to install and try the application. Students are invited to provide ratings and reviews of the Mahasiswa Bugar application through the application feedback feature on the Google Playstore.

\section{Data analysis}

IPAQ and BREQ-2 data obtained from the pre-test and post-test results were then analyzed using statistical analysis techniques paired sample t-test with the Statistical Package for Social Science (SPSS) software.

\section{RESULTS}

The purpose of this research is to create an android application (mobile apps) to measure and provide guidance for independent physical fitness coaching programs for students during the COVID-19 pandemic. The research results will be discussed by dividing it into four subtopics, including the four stages of this research.

\section{Results of the first stage of Needs Analysis and Application Design}

Data in physical activity questionnaires, knowledge of fitness, and student demographic data were collected. Methods, procedures and results have been published elsewhere (Suherman et al., 2019; Sultoni et al., 2019). Based on the results of the analysis carried out in the first stage, it was found that an Android-based application to measure student fitness must have the following features: (1) User Profile Management; (2) Measurement of Body Composition; (3) Measurement of VO2Max by Pacer Test; (4) Measurement of muscle strength and endurance using Push-Up and Curl-up Test; (5) Flexibility Measurement using V-sit and reach; (6) Feedback on each test result; (7) The history or recording of each test result; (8) Recommended fitness training program based on test results.

\section{Results of the second stage of application development}

The application display, which includes these eight features, can be seen in Figure 2. 
User Profile Management. To be able to use this application, the user is required to log in to the application first by using the username and password that were registered previously as shown in Figure 1a. If the user doesn't have an account yet, the user can press the button "Create Account" text at the bottom of the application to create a new account. After the login and authentication process is successful, the user will be directed to the application dashboard display containing the user profile.

Body Composition Measurement. The application dashboard displays the user's fitness profile. Body composition measurements are represented by body mass index and body fat percentage. To find out the body mass index, enter your weight (in $\mathrm{kg}$ ) into the weight box, then the BMI information will appear in the gauge. To find out the Body Fat Percentage, the application will calculate an automatic prediction based on BMI and the body fat score based on the formula (Woolcott \& Bergman, 2018). It will be displayed in the form of a human pictorial gauge.

VO2Max Measurement by Pacer Test. To measure the VO2Max through Pacer test (Meredith $\&$ Welk, 2010), users can use the Pacer menu on the home screen. In the spiderweb graph that appears, a user's fitness score profile is displayed to see their fitness condition. The white point of Vo2max in the graph shows the user's aerobic fitness condition. If the dot is still on the spiderweb, the user's aerobic fitness is low. If the white dot is not there, the user must measure Vo2max by clicking on the Pacer image, and the user will enter the PAR-Q test display. PARQ test is a physical activity readiness questionnaire that is used to screen whether the user is allowed to do the pacer test or not. The user then performs the Pacer test according to the guidelines, and after stopping the test, the test results will come out in the form of a Vo2max score and the number of Pacer levels. These results will be captured in the test history and displayed on the spider web on the home page. 


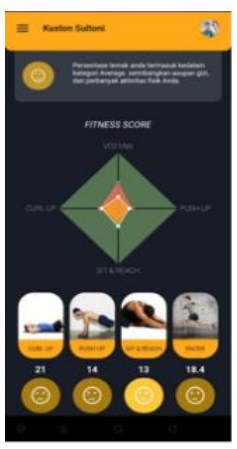

(1)

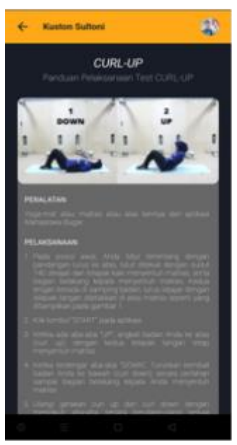

(5)

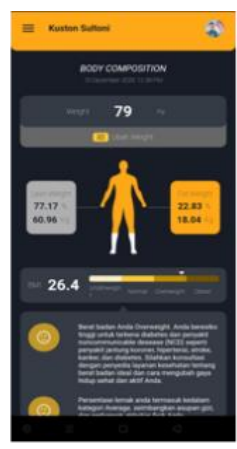

$(2)$

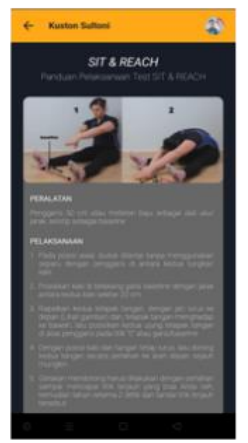

(6)

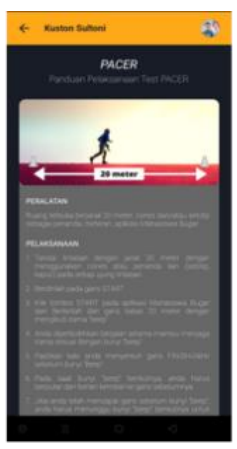

(3)

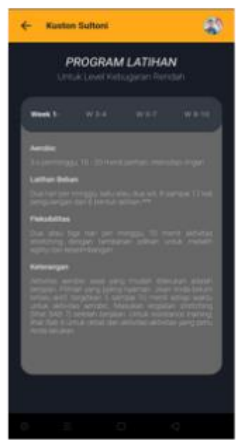

(7)

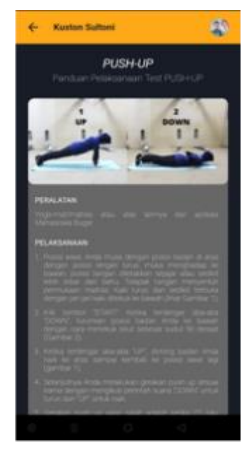

(4)

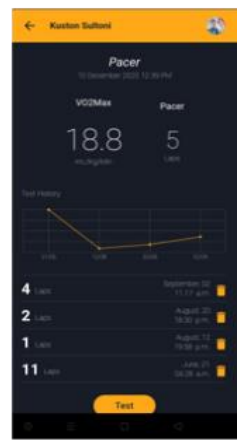

(8)

Figure 2: UI Display Design of Mahasiswa Bugar Application

Measurement of strength and muscle endurance by Push-Up Test. To measure the strength and endurance of the upper body muscles with a push-up test, users can use the push-up test menu on the homepage. Then the user will enter the push-up test guide display (Meredith \& Welk, 2010). Then the user enters the push-up test display and performs the test according to the guidelines, and after stopping the test, the test results will be released in the form of a push-up score. The results will be embedded in the test history and displayed on a spider web on the home page.

Meanwhile, to measure the strength and endurance of the abdominal muscles with the curl-up test, users can use the curl-up test menu on the homepage. Then the user will enter the curl-up test guide display. Then the user enters the curl-up test display and performs the test according to the guidelines, and after stopping the test, the test results will come out in the form of a curlup score. The results will be embedded in the test history and displayed on a spider web on the home page. 
Flexibility Measurement by V-sit and reach. To measure flexibility with the V-sit and reach test, users can use the V-sit and reach menu on the homepage. Furthermore, the user will enter the V-sit and reach test guide display (Cuberek et al., 2013). Then the user enters the V-sit and reach test display and performs the test according to the guidelines, and after stopping the test, the test results will come out in the form of a V-sit and reach score. The results will be embedded in the test history and displayed on a spider web on the home page - feedback of every test result. The fit student application has a feature of providing feedback on each test result conducted by the user. Feedback is given in the form of the user's fitness status based on the results of the fitness tests done. Feedback is prepared based on ACSM's Complete Guide to Fitness \& Health (Bushman, 2017).

\section{Results of stage three Trials and modifications}

The testing and modification phase was carried out by the research team in collaboration with application developers. Testing and modification are carried out based on the ISO 9126 standard regarding the evaluation of computer software programs (Ali, 2018), focusing on functionality, reliability, efficiency, usability, maintainability and portability. After being considered sufficient, the application is published on Google Playstore to make it easier for users to access the Mahasiswa Bugar application for free. The application can be accessed via the following link: or by using the search feature on Google Playstore by entering the keyword "mahasiswa bugar". Figure 3 shows the google playstore screen shoot containing the fit student application.

\section{Results of stage four quasi-experiment pretest-posttest}

About 71 students were initially involved in research and socialization activities on using the Mahasiswa Bugar application. Of these, 48 (68\%) students participated in filling out the instrument, but $31(44 \%)$ were excluded because the data they filled in was incomplete, so that only $40(56 \%)$ participants met the requirements for data processing as stated in table 1. Participants had a mean age of 19 years, consisting of 17 males and 23 females. 


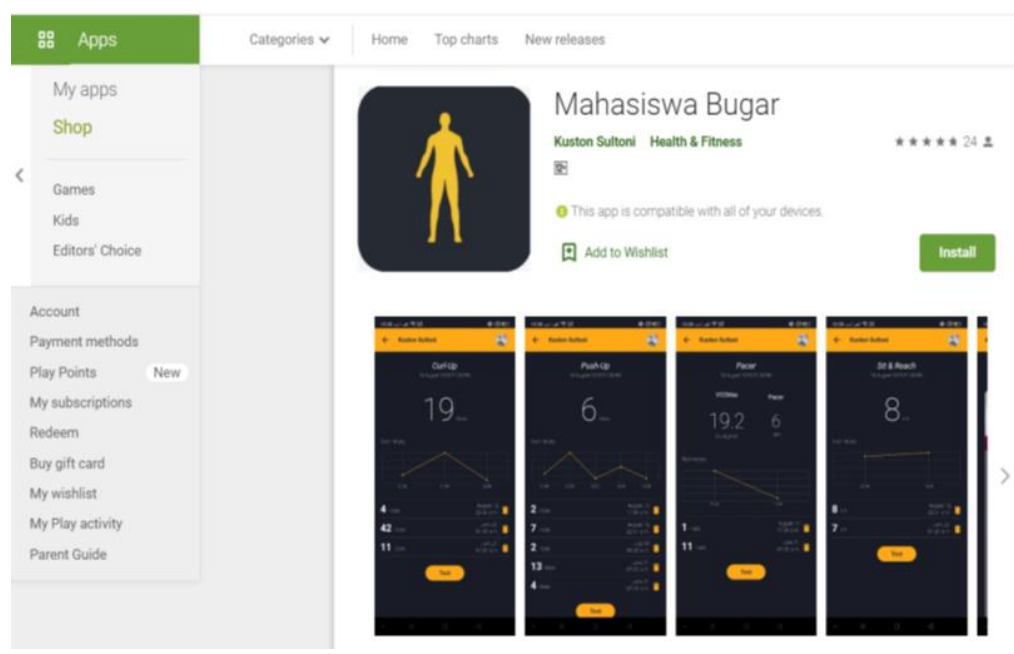

Figure 3: Display of Mahasiswa Bugar Application on Google Playstore

Table 1: Sample Characteristics

\begin{tabular}{ccc}
\hline & $($ mean \pm SD $)$ & $n(\%)$ \\
\hline Age & $19 \pm 0.72$ & \\
Gender & & $17(42.5)$ \\
Male & & $23(57.5)$ \\
Female & & \\
\hline
\end{tabular}

Table 2: Physical Activity and Exercise Motivation

\begin{tabular}{lllll}
\hline & Pre-test & Post-test & $t$ & $P$ \\
\hline Physical Activity & & & & \\
Light, $n(\%)$ & $2(5)$ & $5(12.5)$ & & \\
Moderate, $n(\%)$ & $27(67.5)$ & $21(52.5)$ & & \\
Vigorous, $n(\%)$ & $11(27.5)$ & $14(35)$ & & \\
MET's (M \pm SD) & $2382.93 \pm 1404.01$ & $2553 \pm 1976.76$ & .58 & .57 \\
BREQ 2 (M \pm SD) & $45.18 \pm 11.33$ & $48.55 \pm 9.24$ & 1.93 & .06 \\
\hline
\end{tabular}

Physical activity data (MET's) exercise, as presented in Table 2, shows an increase in the average score based on the initial test results and the final test. Light and moderate PA experienced a percentage increase compared to before the socialization of the fit student application. However, the percentage of Vigorous PA increased by almost $8 \%$. As with the PA data, the average score of training motivation also increased compared to before the socialization was carried out. 
Test data differences between the initial test results and the final test PA calculated by MET's PA, and motivation to exercise using BREQ 2. From this table, it is known that there is no difference in the mean of MET's PA and BREQ between the results of the pre-test and posttest. This means that the socialization of the fit student application does not have a significant effect on PA and exercise motivation, although on average as in Table 2 it has increased.

\section{DISCUSSION}

This study explains using a smartphone application to improve PA and motivation to exercise in students. Socialization of the smartphone application "Mahasiswa Bugar" did not significantly influence MET's PA and motivation to practice. This result contrasts with previous research, which stated that a simple smartphone application significantly increased physical activity for eight weeks in the primary care population (Glynn et al., 2014). The difference in results occurred because the intervention carried out in this study was still limited to socialization and workshops, so the intervention was not optimal. Socialization, which is carried out face-to-face in cyberspace with the Zoom meeting application, maybe one of the insignificant factors of the influence of the intervention. However, if seen from the MET's average score and exercise motivation before and after socialization, it has increased. In addition, the percentage of vigorous PA also increased.

Other studies explain that by giving direct advice (Foster et al., 2013) and individual feedback will be more effective in physical activity intervention efforts, than just providing general information (Middelweerd et al., 2014). This means that face-to-face PA intervention directly (not through cyberspace) will be more effective because it provides participants with specific feedback according to individual characteristics. Nonetheless smartphone applications that promote PA are very popular (Middelweerd et al., 2014) thus providing opportunities to improve an active lifestyle. 
Regarding exercise motivation, it is important to apply behavioral and psychological approaches to increase motivation to exercise (Capdevila Ortís et al., 2007). Although external motivation is needed in an effort to increase the level of exercise, extrinsic motivation plays an important role in maintaining consistency. Smartphone application as a motivation modality can effectively strengthen maintaining PA levels (Al-Eisa et al., 2016). The era of digitalization is the main reason why socialization and intervention in efforts to increase CL must be based on technology.

The limited-time in socializing and intervening smartphone applications for "Mahasiswa Bugar" is one of the weaknesses of this study. Therefore, there needs to be further studies in the future, especially from a longer intervention time. Moreover, the number of samples in future research is expected to involve more students. By involving students from more than one university, it is hoped that research results can be obtained with better validity.

\section{CONCLUSIONS}

The high number of smartphone users among university students is one of the conveniences in socializing physical activity. This study shows that the percentage of student involvement involved in the intervention of smartphone application "Mahasiswa Bugar" on vigorous physical activity has increased. Although the intervention results did not have a statistically significant impact, they could potentially increase involvement in physical activity and motivation in training.

\section{ACKNOWLEDGMENT}

This research was supported by funding from the Ministry of Education and Culture of the Republic of Indonesia, the Directorate General of Higher Education through the Higher Education Excellence Research (PUPT) grant program for the 2018-2020 fiscal year. 


\section{REFERENCES}

Al-Eisa, E., Al-Rushud, A., Alghadir, A., Anwer, S., Al-Harbi, B., Al-Sughaier, N., AlYoseef, N., Al-Otaibi, R., \& Al-Muhaysin, H. A. (2016). Effect of Motivation by "Instagram" on Adherence to Physical Activity among Female College Students. BioMed Research International, 2016, 131-158.

Ali, J. A. (2018). Mobile Applications Quality Evaluation According to ISO 9126 Quality Model Using Nä̈ve Bayes.

Arigo, D., Brown, M. M., Pasko, K., \& Suls. (2020). Social comparison features in physical activity promotion apps: Scoping meta-review. J. of Medical Internet Research, 22(3).

Bushman, B. (2017). ACSM's Complete Guide to Fitness \& Health, 2E (American College of SportsMedicine (ed.)). Human Kinetics.

Capdevila Ortís, L., Niñerola i Maymí, J., Cruz Feliu, J., Losilla Vidal, J. M., Parrado Romero, E., Pintanel Bassets, M., Valero Herreros, M., \& Vives Brosa, J. (2007). Exercise motivation in university community members. Psicothema, 19(2), 250.

Cocca, A., Liukkonen, J., Mayorga-Vega, D., \& Viciana-Ramírez, J. (2014). Healthrelated physical activity levels in Spanish youth and young adults. Perceptual and Motor Skills, 118(1), 247-260.

Cuberek, R., Machová, I., \& Lipenská, M. (2013). Reliability of V sit-and-reach test used for flexibility self-assessment in females. Acta Gymnica, 43(1), 35-39.

Ekelund, U., Dalene, K. E., Tarp, J., \& Lee, I. M. (2020). Physical activity and mortality: What is the dose response and how big is the effect. British J. of Sports Med.,0(0),5-6.

Foster, C., Richards, J., Thorogood, M., Hillsdon, M., Kaur, A., Wickramasinghe, K. K., \& Wedatilake, T. (2013). Remote and web 2.0 interventions for promoting physical activity. Cochrane Database of Systematic Reviews, 2013(2). 
Gall, M. D., Gall, J. P., \& Borg, W. R. (2003). Educational research: An introduction (7th ed.). In Qualitative Voices in Educational Research (7th Editio). Allyn \& Bacon.

Glynn, L. G., Hayes, P. S., Casey, M., Glynn, F., Alvarez-Iglesias, A., Newell, J., Ólaighin, G., Heaney, D., O'Donnell, M., \& Murphy, A. W. (2014). Effectiveness of a smartphone application to promote physical activity in primary care: The SMART MOVE randomized controlled trial. British Journal of General Practice, 64(624), 384391.

Hammami, A., Harrabi, B., Mohr, M., \& Krustrup, P. (2020). Physical activity and coronavirus disease 2019 (COVID-19): specific recommendations for home-based physical training. Managing Sport and Leisure, $0(0), 1-6$.

Kassa, M. ., \& Grace, J. . (2020). Frequency, Intensity, Time, and Type Principle of Physical Activity as a Medical Disability Prevention Program in Ethiopia: A Mixed-method Study. Indian Journal of Public Health, 64(2), 141-147.

Markland, D., \& Tobin, V. (2004). A modification to the behavioural regulation in exercise questionnaire to include an assessment of amotivation. Journal of Sport and Exercise Psychology, 26(2), 191-196.

Mattioli, A. V., \& Ballerini Puviani, M. (2020). Lifestyle at Time of COVID-19: How Could Quarantine Affect Cardiovascular Risk. American Journal of Lifestyle Medicine, 14(3), 240-242.

Meredith, M. D., \& Welk, G. (2010). Fitnessgram and Activitygram Test Administration Manual-Updated 4th Edition. Human Kinetics.

Middelweerd, A., Mollee, J. S., Wal, C. N. van der, Brug, J., \& Velde, S. J. te. (2014). Apps to promote physical activity among adults: A review and content analysis. International Journal of Behavioral Nutrition and Physical Activity, 1-9.

Moser, C., \& Yared, P. (2020). Pandemic Lockdown: The Role of Government 
Commitment. SSRN Electronic Journal.

Nyenhuis, S. M., Greiwe, J., Zeiger, J. S., Nanda, A., \& Cooke, A. (2020). Exercise and Fitness in the Age of Social Distancing During the COVID-19 Pandemic. Journal of Allergy and Clinical Immunology: In Practice, 8(7), 2152-2155.

Pal, R., \& Bhadada, S. K. (2020). COVID-19 and Non- Communicable Diseases. BMJ Journal, 96(March), 429-430.

Piguillem, F., \& Shi, L. (2020). Optimal COVID-19 Quarantine and Testing Policies. EIEF Working Paper, March, 1-38.

Sjödin, H., Wilder-Smith, A., Osman, S., Farooq, Z., \& Rocklöv, J. (2020). Only strict quarantine measures can curb the coronavirus disease (COVID-19) outbreak in Italy, 2020. Eurosurveillance, 25(13), 1-6.

Suherman, A., Sultoni, K., Jajat, J., Risma, R., \& Agust, K. (2019). Physical Self Concept And Physical Activity Among University Students. 1st International Conference on Education, Social Sciences and Humanities (ICESSHum 2019), 335(Advances in Social Science, Education and Humanities Research), 460-465.

Sultoni, K., Suherman, A., \& Fitri, M. (2019). The Effect of Physical Activity Levels on Health-Related Physical Fitness of University Students. 335(ICESSHum), 271-276.

Woolcott, O. O., \& Bergman, R. N. (2018). Relative fat mass (RFM) as a new estimator of whole-body fat percentage - A cross-sectional study in American adult individuals. Scientific Reports, 8(1), 10980.

World Health Organization. (2018). DALY estimates, 2000-2016. June. http://www.who.int/healthinfo/global_burden_disease/GHE2016_DALY_Global_2000_ 2016_.xls?ua $=1$ 